\title{
Analysis of Business Management and Personnel Incentive Theory
}

\author{
Yuxi Han ${ }^{1, a}$ \\ ${ }^{1}$ Pingxiang University, Pingxiang, Jiangxi, 337055 \\ a email
}

\begin{abstract}
Keywords: Business Management, Personnel Incentive Theory, Enterprise Development
\end{abstract}
\begin{abstract}
The 21st century is the competition for talent, human capital is the most important capital. In the knowledge economy era, the traditional advantages of natural resources will gradually be replaced by intelligence. Knowledge, science and technology will become the decisive factor in economic development, more and more wealth to countries with knowledge advantage and technological advantages, regional, businesses and individuals gather. The strength of the country's position in the international competition depends on scientific and technological strength and quality of talent fundamentally. A finding from Harvard University economist Robert Barro showed: hinder poor countries catch up with the rich factor, not a lack of physical capital, but the lack of human capital. Human capital he referred to here actually refers to a knowledge-based talent, high-tech talent. Therefore, in the era of knowledge economy, rich in natural resources is no longer a decisive factor in wealth, intelligence resources, knowledge-based professionals, high-tech talent possession is out of poverty, enhance the comprehensive national strength of the key. Therefore, attention to personnel, particularly those with innovative spirit and ability of high-tech talent, is the focus of competition in the era of knowledge economy.
\end{abstract}

\section{Introduction}

In science and technology, knowledge economy flourish today, corporate human resources are the country's most important strategic resource, is the main driving force of social and economic development, it was decided to improve the ability of independent innovation. However in recent years, the phenomenon of brain drain is very serious. Foreign enterprises not only to attract a large number of people to work abroad, but also actively promote the localization of personnel policy. A large number of talents drain often leads to the loss of markets and technology, thus becoming an important reason hinder the ability of independent innovation improved. So how to motivate business professionals, the maximum possible to retain talent, maximize inspire and mobilize the enthusiasm of business talent, talent to enable enterprises to improve their innovation capability in our capability of independent innovation, has practical significance.

Western thought excitation consists of three parts, one humanity hypothesis theory; the second is rational behavior theory; the third is the need theory. Modern incentive theory is based on the theory of human nature and needs based on the theory, the theory of human nature is to solve logic incentives need to be resolved is the theory of incentives and pathways. According to different studies of different incentive problems, as well as its relationship with the behavior of the Western theory of motivation is divided into three categories: The first is the content type of incentive theory, the theory from the excited behavior maneuvering factor this perspective to study the incentive problem, the theory that the degree of enthusiasm and excited people mainly depends on the degree to meet the need. The second category is the process type incentive theory, the theory from the middle of the process of psychological and behavioral outcomes need to connect this research perspective to study the incentive problem, the theory tries to figure out how to reward employees face the decision to pay the level of effort, and it relates to how employees to assess the rewards, how to choose their own behavior, how to determine the direction of behavior and so on. The third category is behavior modification Incentive theory, which result from the conduct of departure to investigate whether the conduct is excited that tend to be motivated behavior recurring. 


\section{The Importance of Incentives to Improve the Capability of Independent Innovation}

"Motivation is the core of management," the well-known management thinking, is a famous French management guru and outstanding entrepreneurs Fayol and Crete in the 1930s put forward, it has now become the world entrepreneurs consensus. Although management activities were inseparable factors, but the primary and direct object is a person, object management is primarily to have the desired effect through the coordination of human activities. Incentive of modern management is the most important, basic and also the most difficult one of the functions. With the domestic and international market competition, enterprises in order to survive and develop, we must continue to improve their capability of independent innovation, to this end, it is necessary to maximize the incentives of all employees, to fully exploit its inherent potential.

With the rapid development of science and technology, competition in the world economy is becoming increasingly fierce. Competition in comprehensive national strength, scientific and technological strength of the competition, enterprise efficiency competition increasingly depends on the talent competition. How to use management tools maximize the role of human resources be utilized, can make the best use, as the main core of modern management. As long as we seize the core of this incentive, we can fully develop human resources and other management resources through the development of people's initiative effectively; only to excite the core of management, in order to rely on people's role in promoting science, technology, information, intellectual resources development. It can be said in order to stimulate the core of a country's economic management is the key to thriving, but also a business, particularly the commitment to innovation of competitive magic.

Economic prosperity is inseparable from incentive-core management. Japan is a country of late capitalist development, especially after the defeat in World War II, their home is almost in ruins, destitution nationals, but only ten years, from the 1960s, there were so people amazing change, its rapid economic growth, jumped into the ranks of the world's economic powers. In the 1980s, the Japanese economy is even more frightening the US and Western Europe. World politicians, economists Japan this miracle had a keen interest in a variety of research and finally reached the same conclusion: The main reason is also that the management science of human motivation in place. Throughout the business community and government, and education sectors launched a study, research management climax. Advanced management to promote the Japanese economy from the early sixties began to enter a period of rapid development. The study found, leading to Japan's economic growth rate than the United States is the root cause of Japan having appropriate for their circumstances in order to stimulate the core of scientific management. Japanese management pay more attention to the human factor - people-oriented incentives, and potential to play the role of people, relying on people's sense of community and collective cohesion, give full play to the role of people, in line with the use of humane methods of management.

\section{Talent Incentive Mechanism to Establish Specific Measures of Chinese Enterprises}

Growth Incentive. Training of personnel is committed to independent innovation enterprises an important part of product development and management. Especially outstanding product developers are businesses realize their product strategy to remain invincible in the fundamental conditions of competition in the market. This is reflected in:

For staff training can make people better services for enterprises. It seems today is an advanced knowledge are likely to be eliminated in a short time, which must require the speed to keep up with technological development, through continuous re-learning, re-education, upgrading their own knowledge to achieve. This is more pronounced in high-tech fields. Product development is a comprehensive system activity, it requires developers to their product knowledge and technological level of enterprises, the enterprise market environment together.

For businesses high-quality talent, they generally want to improve on the technical level, can make a difference in business. So these people have a strong self-development needs, they welcome a certain level of training. Meanwhile, in competition, the general scientific and technical personnel 
training are as a way to self-improvement. In this regard, training to some extent, has a good incentive.

Since the enterprise competition, is committed to innovation of business entrepreneurs, they would have realized the importance of product development work. Entrepreneurs should also be training for product developers seen as an input to product development. Training is a means to serve multiple purposes, which is already committed to innovation entrepreneurs accepted.

Mental Stimulation. Incentives mental stimulation is very important, it is by meeting employee's social, self-esteem, self-development and self-actualization needs, mobilize staff enthusiasm for work at a higher level, which inspire great depth, to maintain a long time. For business professionals, the high quality and the demand level is higher, inspired by the spirit of its role as a larger motivating employees self-development and the like. Mental stimulation in general has the following manner. Corporate culture is an intangible management, it is from the unplanned, irrational emotional factors to coordinate and control human behavior, give full play to both individual autonomy and innovative spirit, and let his behavior consciously with others to converge to form unity and cooperation as a whole, in order to achieve corporate goals. No matter how large, medium or small business, you must create a good corporate culture. To create a corporate culture not be achieved overnight, but companies can change or promote the formation of corporate culture through process management, and its decision is to coordinate the three key factors (coordination), cooperation (cooperation) and communication (communication), collectively known as 3C factors. The "coordination" is the enterprise to make an analysis of the actual situation, including for strategic objectives, business assets, competitive advantage and changing market environment and so make plenty of reason to resolve this in favor of corporate staffing departments of coordination between, on the combination of relationship, so that enterprises always with the latest market trends oriented, pro-competitive enterprises. "Cooperation" in the process promoting everyone at work talk to each other resources, concerted efforts to solve problems and make decisions together to create a spirit of solidarity, the formation of a shared cultural atmosphere, which will help to improve interpersonal between employees relationship. "AC" Let the flow of data, information and knowledge can flow freely therein, to facilitate the use of employees, if necessary, its mode of operation is that each employee can put the knowledge and difficulties come to share research with other employees. So that knowledge can open, share, and communicate in the flexible use. "3C" enables companies to develop business goals and objectives in the operation, so that share common values and a sense of responsibility among employees. Process leaders of all activities in the process will make the enterprise generates a certain image in the public mind, the corporate image is good or bad, will affect the internal staff of mental activity and behavior orientation. Therefore, enterprises need to establish a good corporate culture, motivate staff enthusiasm, enthusiasm, initiative and creativity.

For the future of human capital investment mechanism is more and more enterprises of all ages. In this investment mechanism: Talent won the "employability" of cohesion has become a new business location. As a well-known foreign companies in their employment contract are talking about: "Our company is facing the era of rapidly changing technology market and the fierce competition we need flexibility, add or stop the production of products, always turn off or turn on the device. While we can not guarantee a continuation of the work we can not even guarantee the future of the employment relationship, but we will ensure that all employees have the ability to full employment, which can not be found or the ability to work in a new place. "

\section{Conclusion}

Today, science and technology are the primary productive forces, the continued development of high-tech enterprises must rely on people, talent is the core competitiveness of enterprises, enhance the competitiveness of high-tech companies rely heavily on human resources, especially high-tech talent. S \& T Talent limited the total amount, the relative lack of high-tech talent, especially high-tech enterprises in the high-tech talent, is in high-speed flows. Brain drain caused by the high-tech science and technology enterprises in a variety of reasons in talent incentive mechanism is 
not perfect is an important factor. Current academic research from a more general enterprise talent incentive mechanism for enterprises in a knowledge-based talent, high-tech talent incentive mechanism is less theoretical results were studied, but not very deep. And also the general study of talent incentive mechanism, and talent in general talent, knowledge, talent, and other high-tech talent did not classify targeted research.

\section{Acknowledgements}

2015 College of Humanities and social science research projects in Jiangxi Province (TQ1516). 2014 Jiangxi Education Reform Project (JXJG-14-22-6).

Educational examination and enrollment system reform in Jiangxi Province scientific research projects (1524).

2015 Education Department of Jiangxi Party Building topics (JXGXDJKT.GH-201513).

Jiangxi IP soft science research project (ZR201610).

\section{References}

[1] Alchian.A., H Demsetz.Production, Information Cost and Economic Organization. The American Economist. 1972.

[2] Peter Drucker. The Coming of the New Organization. Harvard Business. 1998.

[3] Ndelela. L. T. Establishing a knowledge management programmer for competitive advantage in an enterprise. International Journal of Information Management. 2001.

[4] Herriot P, Manning E G, Kidd J M. The content of the psychological contract. British Journal of Management. 1997.

[5] Prendergast C. The role of promotion in inducing specific human capital acquisition. Quarterly Journal. 1993.

[6] Alchian, A, and H Demsetz." Production, Information Cost and Ecomomic Organization". The American Economist. 1972. 